\title{
SODIUM/HYDROGEN EXCHANGER INHIBITION REDUCES MYOCARDIAL REPERFUSION EDEMA AFTER NORMOTHERMIC CARDIOPLEGIA
}

Francesco Paolo Tritto, MD*

Javier Inserte, ScD

David Garcia-Dorado, MD

Marisol Ruiz-Meana, DVM

Jordi Soler-Soler, MD
Objective: The hypothesis was that $\mathrm{Na}^{+} / \mathrm{H}^{+}$exchange occurring during normothermic cardioplegia contributes to the development of myocardial edema during subsequent reperfusion and impairs functional recovery. Methods: Rat hearts were perfused in a Langendorff apparatus and submitted to 60 minutes of normothermic cardioplegia and 90 minutes of reperfusion. Hearts were allocated to one of four groups $(n=8)$ : inhibition of $\mathrm{Na}^{+} / \mathrm{H}^{+}$exchanger with HOE642 throughout the whole experiment (HOE group), only during cardioplegia (HOE-C) or during reperfusion (HOE-R), and a control group. Results: In HOE and HOE-C groups, myocardial water content at the end of reperfusion was lower than in the HOE-R and control groups $(526 \pm 19$ and $533 \pm 18 \mathrm{ml} / 100 \mathrm{gm}$ dry tissue vs $632 \pm 25$ and $634 \pm 17 \mathrm{ml} / 100 \mathrm{gm}$ dry tissue, respectively, $p=0.001$ ), left ventricular end-diastolic pressure increased less after reperfusion (46.6 \pm 9.7 and $63.2 \pm 10.0 \mathrm{~mm} \mathrm{Hg}$ vs $75.1 \pm 4.3 \mathrm{~mm} \mathrm{Hg}$ and $85.7 \pm 8.9 \mathrm{~mm} \mathrm{Hg}$, respectively, $p=\mathbf{0 . 0 0 6}$ ), and recovery of left ventricular developed pressure was better $(46.7 \%$ and $45.8 \%$ vs $4.5 \%$ and $9.8 \%, p=0.048)$. Relative to the control group, total lactate dehydrogenase release during reperfusion was reduced by $80.2 \%, 69.3 \%$ and $36 \%$ in HOE, HOE-C, and HOE-R groups, respectively. Conclusion: Inhibition of the $\mathrm{Na}^{+} / \mathrm{H}^{+}$exchange during normothermic cardioplegia reduces myocardial edema and necrosis during subsequent reperfusion, improving functional recovery. Inhibition of $\mathrm{Na}^{+} / \mathrm{H}^{+}$ exchange during reperfusion only has a much smaller effect. (J Thorac Cardiovasc Surg 1998;115:709-15)
$\mathrm{T}_{\mathrm{r} e \mathrm{din}}^{\mathrm{h}}$ he association of hypothermia and diastolic arrest has long been the mainstay of myocardial protection. ${ }^{1}$ However, its use has been associated

From Laboratorio de Cardiologia Experimental B. Servicio de Cardiologia, Hospital General Universitari Vall d'Hebron, Barcelona, Spain.

Supported in part by the European Commission (Biomed II PL 95/1254), Fondo de Investigation Sanitaria de la Seguridad Social (FIS 97/0948), and Hospital General Universitari Vall d'Hebron (RCHG 96/82).

Received for publication Dec. 23, 1996; revisions requested April 15, 1997; revisions received May 12, 1997; accepted for publication August 18, 1997.

Address for reprints: David Garcia-Dorado, MD, Laboratorio de Cardiologia, Experimental B, Servicio de Cardiologia, Hospital General Universitari Vall d'Hebron, Pg. Vall d'Hebron 119-129, 08035 Barcelona, Spain.

*F. P. Tritto was the winner of the Francis Fontan Prize 1995 fellowship from the European Association for Cardio-Thoracic Surgery. Present address: Via Manzoni, 52. 80123 Naples, Italy.

Copyright (C) 1998 by Mosby, Inc.

$0022-5223 / 98 \$ 5.00+0 \quad \mathbf{1 2} / \mathbf{1} / \mathbf{8 5 9 9 1}$ with modifications in the enzyme function, membrane stability, calcium homeostasis, glucose use, adenosine triphosphate generation and use, and $\mathrm{pH}$ and water control. ${ }^{2,3}$ Normothermic cardiac arrest may afford adequate protection, ${ }^{4}$ but no large-scale controlled studies have assessed the clinical efficacy and safety of this technique. ${ }^{5}$ Myocardial edema is a prominent feature of postcardioplegic reperfusion. ${ }^{6}$ It reduces ventricular performance and compliance and limits coronary flow during reperfusion. ${ }^{7}$ The mechanism of myocardial edema is not perfectly understood. During myocardial ischemia, accumulation of diffusible catabolites increases osmotic pressure on both sides of the sarcolemma. ${ }^{8}$ Subsequent reperfusion results in a rapid washout of extracellular catabolites, generation of an osmotic gradient, and water influx to the intracellular space. ${ }^{9}$

The contribution of $\mathrm{Na}^{+} / \mathrm{H}^{+}$exchange to the genesis of reperfusion myocardial edema has been only recently recognized. The $\mathrm{Na}^{+} / \mathrm{H}^{+}$exchanger is a ubiquitous sarcolemmal transporter that contributes to regulation of cell volume in many cell types ${ }^{10}$ 


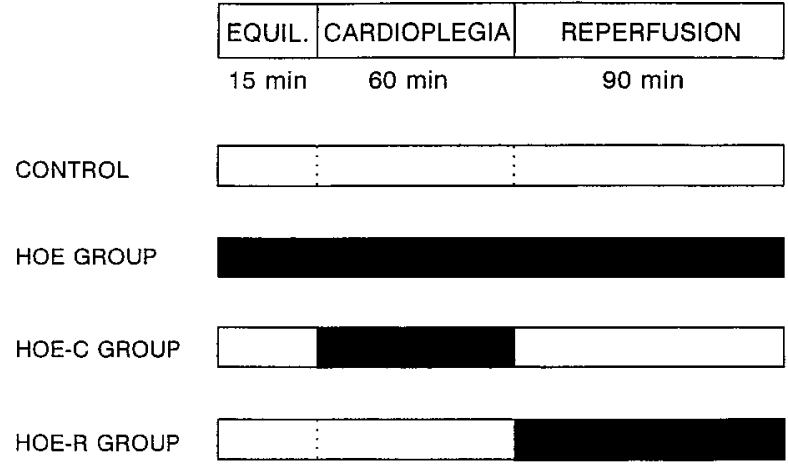

HOE642

Fig. 1. Experimental protocol. Hearts were subjected to 15 minutes of equilibration perfusion (EQUIL) with modified Krebs-Henseleit solution, 60 minutes of St. Thomas' Hospital cardioplegic solution number 2 (CARDIOPLE$G I A$ ), and 90 minutes of reperfusion with modified KrebsHenseleit solution (REPERFUSION). In the HOE group, HOE642 at the dose of $7 \mu \mathrm{mol} / \mathrm{L}$ was added both to the modified Krebs-Henseleit solution and to St. Thomas' Hospital cardioplegic solution number 2. In the HOE-C group, HOE642 was added only to the cardioplegic solution. In the HOE-R group, HOE642 was added only to the reperfusion solution. Temperature of all solutions was kept between $34^{\circ}$ and $37^{\circ} \mathrm{C}$.

and is stimulated during hypoxia ${ }^{11}$ in response to excessive $\mathrm{H}^{+}$production. ${ }^{12}$ Recent studies have demonstrated the important role of $\mathrm{Na}^{+} / \mathrm{H}^{+}$exchange occurring during hypoxia in the genesis of reoxygenation-induced myocardial edema ${ }^{13}$ and the ability of HOE642, a highly selective inhibitor of type $1 \mathrm{Na}^{+} / \mathrm{H}^{+}$exchanger, ${ }^{14}$ to prevent it. The purpose of this study was to test the hypothesis that $\mathrm{Na}^{+}$gain related to $\mathrm{Na}^{+} / \mathrm{H}^{+}$exchange taking place during warm cardioplegic ischemia induces water uptake and edema formation during subsequent myocardial reperfusion, impairing functional recovery.

\section{Materials and methods}

Experimental model. This study was performed in the isolated perfused rat heart model. Animals were handled according to the Recommendations of the Declaration of Helsinki and the Guiding Principles in the Care and Use of Animals, and the study was approved by the Research Commission of the Hospital Universitari Vall d'Hebron. Sprague-Dawley rats (300 to $400 \mathrm{gm})$ were deeply anesthetized with thiopental sodium $(100 \mathrm{mg} / \mathrm{kg}$ intraperitoneally). Hearts were rapidly excised, placed in ice-cold saline solution, and prepared for positioning on a nonrecirculating Langendorff apparatus. The aorta was cannu- lated, and orthograde perfusion of the coronary circulation was quickly started with the oxygenated buffer solution at a temperature of $37^{\circ} \mathrm{C}$.

Experimental protocol. Perfusion protocol consisted of an equilibration period of 15 minutes, 60 minutes of cardioplegic arrest, and 90 minutes of reperfusion.

Solutions. During equilibration and reperfusion periods, a modified Krebs-Henseleit bicarbonate buffer solution was used. This solution contained $140 \mathrm{mmol} / \mathrm{L}$ sodium chloride, $24 \mathrm{mmol} / \mathrm{L}$ sodium bicarbonate, 2.7 $\mathrm{mmol} / \mathrm{L}$ potassium chloride, $0.4 \mathrm{mmol} / \mathrm{L}$ monobasic potassium phosphate, $1 \mathrm{mmol} / \mathrm{L}$ magnesium sulfate, 1.8 $\mathrm{mmol} / \mathrm{L}$ calcium chloride and $5 \mathrm{mmol} / \mathrm{L}$ glucose. It was prepared daily. The buffer was continuously gassed with $95 \%$ oxygen and $5 \%$ carbon dioxide at $37^{\circ} \mathrm{C}(\mathrm{pH} 7.4)$. The cardioplegic solution used was St. Thomas' Hospital solution number 2 (Plegisol; Abbott Laboratories, Chicago, Ill.) to which sodium bicarbonate was added to obtain a $\mathrm{pH}$ of 7.8 according to the manufacturer's specifications.

$\mathrm{Na}^{+} / \mathrm{H}^{+}$exchange inhibition. $\mathrm{Na}^{+} / \mathrm{H}^{+}$antiport was blocked with HOE642 (Hoechst AG, Frankfurt Main, Germany) at a concentration of $7 \mu \mathrm{mol} / \mathrm{L}$. This concentration has been shown to prevent rigor contracture in metabolically inhibited isolated myocytes, ${ }^{15}$ to limit reoxygenation edema in the isolated rat heart, ${ }^{13}$ and to reduce infarct size in pigs. ${ }^{16}$ All solutions containing HOE642 were protected from direct light throughout the experiment because of photosensitivity.

Groups of study. Flow rate was adjusted at $10 \mathrm{ml} / \mathrm{min}$ during equilibration. This required a coronary perfusion pressure of $58 \pm 4 \mathrm{~mm} \mathrm{Hg}$. The cardioplegic solution, St. Thomas' Hospital solution number 2, was delivered through a lateral derivation of the perfusion apparatus at the rate of $5 \mathrm{ml} / \mathrm{min}$ for 2 minutes at $37^{\circ} \mathrm{C}$. Arrested hearts were immersed in the same cardioplegic solution, with temperature maintained between $34^{\circ}$ and $37^{\circ} \mathrm{C}$. Reperfusion was produced by restoring flow at $10 \mathrm{ml} / \mathrm{min}$. Hearts were allocated to one of four groups $(n=8$ in each group; Fig. 1). In one group, $7 \mu \mathrm{mol} / \mathrm{L}$ HOE642 was added to the equilibration, cardioplegic, and reperfusion solutions (HOE group). To investigate whether $\mathrm{Na}^{+} / \mathrm{H}^{+}$ antiport inhibition was effective during cardioplegia or during reperfusion, HOE642 was added to only the cardioplegic solution in a second group (HOE-C group) and to only the reperfusion solution in a third group (HOE-R group). Finally, HOE642 was not added to any of the solutions in a control group.

The effect of cardioplegia without reperfusion on myocardial water content was analyzed in an additional series of experiments. In these series, hearts were perfused as the HOE or the control group $(n=4)$ and removed from the Langendorff system 1 hour after cardioplegic arrest without reperfusion.

\section{Measurements}

Functional data. Left ventricular pressure was monitored by introducing a fluid-filled latex balloon in the cardiac cavity through the left atrium, placed at the tip of a Cordis 5F catheter (Cordis Corporation, Miami, Fla.) connected to a Baxter $43600 \mathrm{~F}$ pressure transducer (Baxter S.A., Valencia, Spain). The balloon was inflated with saline solution to keep left ventricular end-diastolic pressure (LVEDP) between 10 and $12 \mathrm{~mm} \mathrm{Hg}$ during the 
Table I. Hemodynamic results in the four groups of study

\begin{tabular}{cccccc}
\hline & Equilibration & Cardioplegia & & \multicolumn{2}{c}{ Reperfusion } \\
\cline { 3 - 5 }$(15 \mathrm{~min})$ & $(30 \mathrm{~min})$ & $30 \mathrm{~min}$ & $60 \mathrm{~min}$ & $90 \mathrm{~min}$ \\
\hline LVEDP (mm Hg) & $10.6 \pm 1.2$ & $43.7 \pm 6.3$ & $46.6 \pm 9.7^{* \dagger}$ & $51.0 \pm 11.4$ & $55.8 \pm 10.8$ \\
HOE group & $11.0 \pm 2.1$ & $52.7 \pm 7.6$ & $63.2 \pm 10.0$ & $53.3 \pm 8.1^{*}$ & $56.6 \pm 9.2$ \\
HOE-C group & $10.8 \pm 2.3$ & $56.0 \pm 6.4$ & $75.1 \pm 4.3$ & $68.6 \pm 6.4$ & $62.0 \pm 11.6$ \\
HOE-R group & $10.2 \pm 1.5$ & $45.4 \pm 7.1$ & $85.7 \pm 8.9$ & $71.7 \pm 8.5$ & $66.8 \pm 7.2$ \\
Control group & & & & & \\
LVDP (mm Hg) & $69.4 \pm 8.4$ & - & $32.4 \pm 9.2^{* \dagger}$ & $20.3 \pm 2.1$ & $17.9 \pm 3.3^{* \dagger}$ \\
HOE group & $75.2 \pm 6.4$ & - & $34.4 \pm 1.5^{* \dagger}$ & $35.8 \pm 9.3^{*} \dagger$ & $27.5 \pm 1.4$ \\
HOE-C group & $67.5 \pm 5.1$ & - & $6.6 \pm 2.3$ & $6.4 \pm 2.1$ & $2.8 \pm 1.6$ \\
HOE-R group & $71.7 \pm 5.6$ & & $3.1 \pm 6.3$ & $15.3 \pm 8.7$ & $11.1 \pm 4.3$ \\
Control group & & & &
\end{tabular}

All values expressed as mean \pm standard error.

${ }^{*} p<0.05$ vs control group.

$\dagger p<0.05$ vs HOE-R group.

equilibration period. The signal was digitized and continuously recorded on hard disk with the aid of ad hocdeveloped software. Heart rate, left ventricular systolic pressure, and LVEDP were continuously monitored. Left ventricular developed pressure (LVDP) was calculated as the peak systolic pressure minus the LVEDP and expressed as the percent of the basal value at the end of the equilibration period.

Lactate dehydrogenase $(\mathrm{LDH})$ release. Heart injury during reperfusion was assessed by analysis of LDH release. LDH activity was assayed by spectrophotometric analysis (SLT Spectra Vision, Grödig, Austria) in $0.05 \mathrm{~mol} / \mathrm{L}$ phosphate buffer (monobasic potassium phosphate; dibasic potassium phosphate, $1 \mathrm{mmol} / \mathrm{L}$ sodium pyruvate, and $0.3 \mathrm{mmol} / \mathrm{L}$ reduced nicotinamide adenine dinucleotide. Results were expressed as units of activity (IU) released per gram dry weight. LDH activity was measured in samples taken from the coronary effluent at 1, 2, 3, 4, 6, 8, and 10 minutes and then every 10 minutes until 90 minutes of reperfusion.

Myocardial water content. At the end of the reperfusion period, hearts were removed from the Langendorff apparatus and total myocardial water content was analyzed as previously described elsewhere. ${ }^{17}$ Tissue samples corresponding to about one third of the heart were obtained immediately after removal of the hearts and were rapidly introduced into assay tubes that had been weighed 1 hour before on a high-precision scale (Mettler AJ50; Mettler Instruments, Greifensee, Switzerland). The tubes with the samples were weighed immediately before and after 24 hours of desiccation at $100^{\circ} \mathrm{C}$ (Selecta 200; J. P. Selecta, S.A., Abrera, Spain). Myocardial water content was calculated as the difference between wet and dry weights and expressed as milliliters per 100 grams dry weight.

Statistical analysis. Commercially available software was used for statistical analysis (SPSS/PC+ V4.0; SPSS, Inc., Chicago, Ill.). Statistical comparisons between groups were performed by analysis of variance after having assessed the data for normal distribution. Individual comparisons were performed by means of the less significant difference test. The relationship between myocardial water content and function recovery was investi- gated by means of linear regression analysis. A critical $p$ value of 0.05 was used for all tests. All values are expressed as mean \pm standard error of the mean.

\section{Results}

Functional data. Results of left ventricular function measurements in the four study groups are summarized in Table I. There were no differences between groups at baseline. The maximal elevations of LVEDP during cardioplegic arrest were similar among all groups analyzed and were reached at similar times $(34.1 \pm 1.5,26.7 \pm 1.5,31.1 \pm 1.1$, and $31.2 \pm 1.5$ minutes in the HOE, HOE-C, HOE-R, and control groups, respectively; $p$ not significant). During reperfusion, $\mathrm{HOE}$ and $\mathrm{HOE}-\mathrm{C}$ groups showed a similar functional outcome, significantly better than that observed in HOE-R and control groups. The effects of HOE642 on the changes in LVEDP and LVDP throughout the experiment are shown in detail in Fig. 2. The presence of HOE642 in the cardioplegic solution did not modify LVEDP during normothermic cardioplegic arrest, but it did prevent the increase in LVEDP and improve recovery of LVDP during the first 30 minutes of reperfusion. After 50 minutes of reperfusion, there was a loss of contractile activity in both groups (from 60 to 90 minutes, $p$ not significant).

LDH-release. No study group showed a peak of enzyme release on reperfusion. A small, sustained LDH release was observed throughout the reperfusion period in the control group. In the $\mathrm{HOE}$ and HOE-C groups, only minimal LDH release was observed during reperfusion, whereas the HOE-R group showed an intermediate result (Fig. 3). 


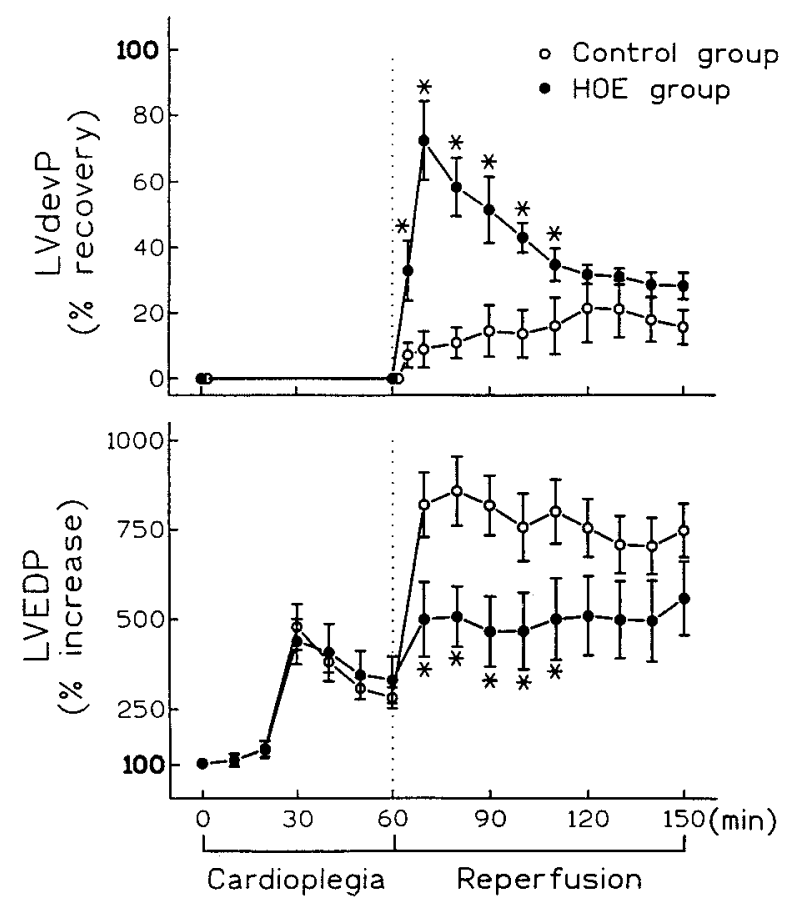

Fig. 2. Functional results during cardioplegic and reperfusion period in control and HOE groups. LVEDP was measured as percentage increase, related to a 10 to $12 \mathrm{~mm}$ $\mathrm{Hg}$ fixed value in the equilibration period. LVDP $(L V \operatorname{dev} P)$ was measured as percentage recovery, related to the baseline LVDP of the equilibration period. Each point is expressed as mean \pm standard error of the mean. Asterisk indicates $p<0.05$ between groups.

Myocardial edema. Myocardial water content in the different study groups is shown in Fig. 4. In the two series of nonreperfused hearts, water content was significantly lower than in reperfused hearts (399 $\pm 8 \mathrm{ml} / 100 \mathrm{gm}$ dry tissue in nonreperfused hearts vs $581 \pm 24 \mathrm{ml} / 100$ gm dry tissue in reperfused hearts, $p=0.001$ ). Reperfusion resulted in lower myocardial water contents in the $\mathrm{HOE}$ and HOE-C groups $(526 \pm 20$ and $533 \pm 18 \mathrm{ml} / 100 \mathrm{gm}$ dry tissue, respectively) than in the HOE-R and control groups $(632 \pm 25$ and $634 \pm 17 \mathrm{ml} / 100 \mathrm{gm}$ dry tissue, respectively; $p=0.006$ ).

Functional data versus water content. Linear regression analysis demonstrated a close relationship between myocardial water content and functional parameters during the reperfusion period. After 30 minutes of reperfusion, LVEDP was directly correlated $(r=0.9364, p=0.001)$ and LVDP was inversely correlated $(r=-0.815, p=0.001)$ with myocardial water content (Fig. 5).

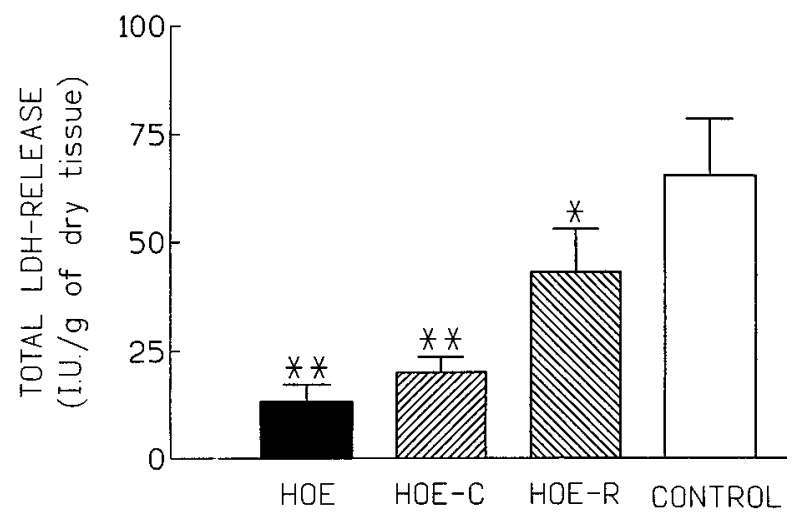

Fig. 3. Total $\mathrm{LDH}$ release throughout 90 minutes of reperfusion in HOE, HOE-C, HOE-R, and control groups. Error bars correspond to standard error of the mean. Asterisk represents $p=0.032$ vs control group; double asterisk represents $p<0.01$ vs control group and HOE-R group.

\section{Discussion}

This study analyzed the effect of inhibition of $\mathrm{Na}^{+} / \mathrm{H}^{+}$exchange on the effectiveness of myocardial protection afforded by normothermic cardioplegia in the isolated, crystalloid-perfused rat heart. Addition of HOE642 to the cardioplegic solution resulted in less myocardial edema, less enzyme release, and improved functional recovery during subsequent reperfusion. Addition of HOE642 to the reperfusion medium did not significantly enhance this protective effect. These results indicate that harmful $\mathrm{Na}^{+} / \mathrm{H}^{+}$exchange takes place during normothermic cardioplegia and that its pharmacologic inhibition may result in improved myocardial protection.

Previous studies. It has been shown that $\mathrm{Na}^{+} / \mathrm{H}^{+}$ exchange inhibition during ischemia or anoxia reduces myocardial necrosis during subsequent reperfusion or reoxygenation. ${ }^{12,13,16}$ The effects of inhibition of $\mathrm{Na}^{+} / \mathrm{H}^{+}$exchange during cardioplegia have been less well investigated, and the effect of $\mathrm{Na}^{+} / \mathrm{H}^{+}$exchange on postcardioplegic myocardial edema has not yet been described. Because the activity of $\mathrm{Na}^{+} / \mathrm{H}^{+}$sarcolemmal exchanger is markedly depressed by hypothermia, ${ }^{18}$ the addition of $\mathrm{Na}^{+} / \mathrm{H}^{+}$exchange inhibition during hypothermic cardioplegia should be of little use. However, improved myocardial preservation has been recently described when $1 \mu \mathrm{mol} / \mathrm{L}$ HOE642 was added during hypothermic cardiac arrest to St. Thomas' Hospital cardioplegic solution number 2 for 12 hours at 


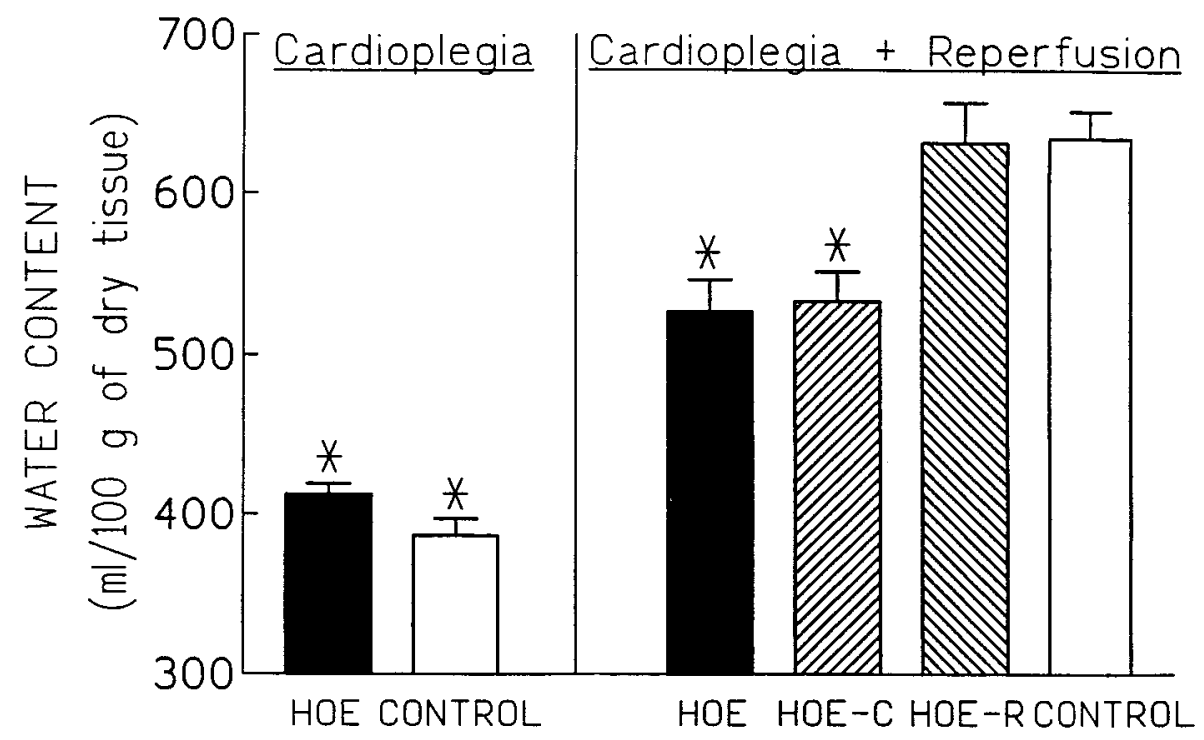

Fig. 4. Water content is expressed as difference between wet and dry heart weights, measured after 24 hours of desiccation at $100^{\circ} \mathrm{C}$. Measurements were performed without reperfusion (Cardioplegia) or after 90 minutes of reperfusion (Cardioplegia + Reperfusion). Each group is represented as mean value \pm standard error of the mean. Asterisk represents $p=0.001$ vs control group in the cardioplegia plus reperfusion study.

$4^{\circ} \mathrm{C}^{19}$ or when HOE694 was added for 5 hours at $7.5^{\circ} \mathrm{C}$ and for 2 hours at $28^{\circ} \mathrm{C}^{20}$

Normothermic cardioplegia was selected in this study because several recent studies have described the potential advantages of this type of protection compared with hypothermia, ${ }^{2,3,5}$ and because hypothermia cannot be performed in patients with cryoagglutinins. ${ }^{4}$ St. Thomas' Hospital solution is widely used $^{21}$ because of its convenience and low price. This solution contains bicarbonate in its composition. Previous studies indicate that $\mathrm{HCO}_{3}{ }^{-} / \mathrm{Na}^{+}$ symport represents a complementary route of $\mathrm{Na}^{+}$ entry to cardiac cells during energy deprivation, and that removal of bicarbonate from the extracellular media and addition of HOE642 have additive beneficial effects against hypercontracture and swelling induced by subsequent reoxygenation. ${ }^{13}$ The beneficial effects of HOE642 on edema and function of reperfused myocardium could be even more important when added to bicarbonate-free cardioplegic solutions.

Important myocardial edema has been shown to occur during reperfusion after regional normothermic ischemia ${ }^{9}$ and hypothermic cardioplegia. ${ }^{7,22}$ This edema was explained as a consequence of the osmotic gradient generated by the abrupt normalization of extracellular osmotic pressure, and it could be limited by hyperosmotic reperfusion. ${ }^{8,17}$ It has also been shown recently that myocardial reoxygenation after hypoxia may induce severe myocardial edema and that $\mathrm{Na}^{+} / \mathrm{H}^{+}$exchange plays an important role in its genesis. ${ }^{13}$ Myocardial edema may have detrimental effects on contractile and microvascular function of reperfused myocardium, ${ }^{7,18}$ and swelling may contribute along with hypercontracture and cytoskeletal fragility to sarcolemmal rupture and cell death on restoration of oxygen supply. ${ }^{15}$ This study describes myocardial edema assessed from measurement of total water content after normothermic cardioplegia. The fact that $\mathrm{Na}^{+} / \mathrm{H}^{+}$exchange inhibition alters this parameter demonstrates that $\mathrm{Na}^{+} / \mathrm{H}^{+}$exchange is involved in edema formation, but whether the edema is the direct result of $\mathrm{Na}^{+}$transport remains to be determined.

In this study, a narrow correlation was found between myocardial water content and functional parameters after 30 minutes of reperfusion, a moment when myocardial edema has already reached values virtually identical to those observed at the end of the 90-minute normoxic perfusion period. ${ }^{13}$ This narrow correlation is consistent with the working hypothesis of this study and with previous observations suggesting that myocardial edema has a 

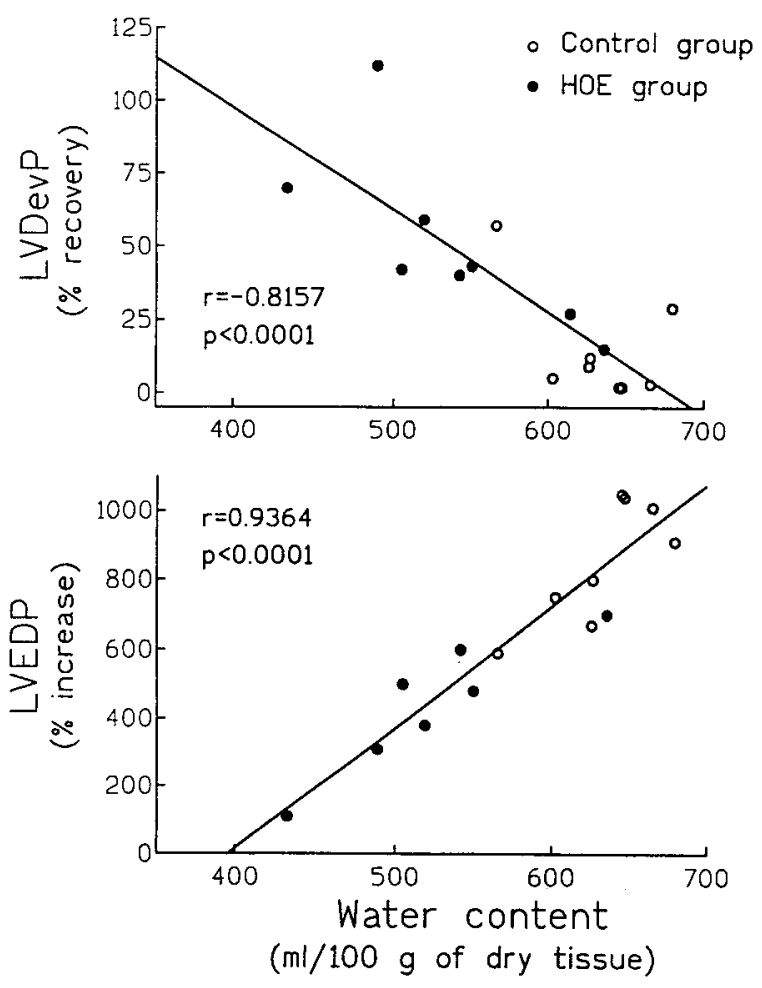

Fig. 5. Regression analysis of functional results versus myocardial water accumulation. Regression lines were calculated for values obtained from control and HOE groups. Each symbol represents one heart. LVEDP increase after 30 minutes of reperfusion is expressed as a percentage of basal LVEDP at the end of the equilibration period. LVDP ( $L V D e v P)$ recovery after 30 minutes of reperfusion is expressed as a percentage of LVDP measured at the end of the equilibration period.

detrimental influence on contractile function, although a causal relationship has not yet been established. ${ }^{23}$ It has been shown that osmotic stress may reduce $\mathrm{Ca}^{2+}$ sensitivity in rat myocardium, ${ }^{24}$ that swelling may increase spatial separation between contractile filaments, ${ }^{25}$ and that moderate hypertonicity of the perfusion buffer improves contractility in the working rat heart. ${ }^{26}$ On the other hand, other studies suggest that myocardial function may influence myocardial water content. In the isolated heart, diminished contractility may result in myocardial edema, ${ }^{27}$ and changes in intracellular volume may modulate $\mathrm{Na}^{+} / \mathrm{H}^{+}$exchange and influence intracellular $\mathrm{pH}^{28}$ Finally, although enzyme release was small in all groups, it cannot be ruled out that a beneficial effect of $\mathrm{Na}^{+} / \mathrm{H}^{+}$inhibition on $\mathrm{Ca}^{2+}$ overload during reperfusion could have resulted in less cell death and better functional recovery.

Critique of the methods. Crystalloid perfusion of the isolated heart is associated to myocardial edema. ${ }^{13,23}$ Under normoxic conditions, myocardial water content increases during the first $30 \mathrm{~min}$ of crystalloid perfusion and stabilizes thereafter. ${ }^{13}$ This perfusion-associated edema is due to the lack of oncotic strength of the crystalloid perfusate, but changes in myocardial water content induced by subsequent anoxia and reoxygenation are largely independent of the oncotic pressure of the buffer. ${ }^{13}$ The model used thus seems valid to analyze the changes in reperfusion edema in response to treatments, although the magnitude of these changes must be measured in relation to a higher value of myocardial water content.

Although desiccation is the method most widely used to measure myocardial water content, it is not an ideal method. First, its results may be influenced by the time between the end of reperfusion and weighing, and by the number and strength of beats occurring during this period. The fact that this period was minimal and similar in all the study groups, however, makes it extremely unlikely that the observed intergroup differences in myocardial water content are artifactual. Second, it does not allow discrimination between intracellular and extracellular edema.

In this study, a small but sustained enzyme release was observed throughout the reperfusion period in all treatment groups, and functional recovery during reperfusion was incomplete. The normothermic cardioplegia protocol used thus affords incomplete myocardial protection against 60 minutes of ischemia. This could be due in part to the large increase in LVEDP favored by the isovolumic conditions, probably greater than those observed during cardiac surgery in human patients. Moreover, the loss of myocardial function observed at the end of the reperfusion period probably reflects progressive deterioration of the preparation associated with crystalloid perfusion. However, the model used allowed the detection of a greater and faster initial recovery of left ventricular function when HOE642 was added to the cardioplegic solution.

Implications. This study was conducted in an asanguineous, nonworking crystalloid-perfused rat heart, and its conclusions therefore cannot be directly extrapolated to the clinical situation. The advantages of blood compared with pure crystalloid perfusion are well known. ${ }^{29}$ Blood vehicle for car- 
dioplegic delivery blends normal oncotic strength and viscosity with buffering capacity, hormonal effects, antioxidant properties, and other advantages associated with the presence of blood factors. ${ }^{30}$ The presence of oxygen in blood cardioplegic preparations helps to satisfy oxygen demand, already reduced by loss of the electromechanical activity.

\section{REFERENCES}

1. Mauney MC, Kron IL. The physiologic basis of warm cardioplegia. Ann Thorac Surg 1995;60:819-23.

2. Vaughn CC, Opie JC, Florendo FT, Lowell PA, Austin J. Warm blood cardioplegia. Ann Thorac Surg 1993;55:1227-32.

3. Lichtenstein SV, Ashe KA, El Dalati H, Cusimano RJ, Panos A, Slutsky AS. Warm heart surgery. J Thorac Cardiovasc Surg 1991;101:269-74.

4. Christakis GT, Koch JP, Deemar KA, Fremes SE, Sinclair L, Chen E, et al. A randomized study of the systemic effects of warm heart surgery. Ann Thorac Surg 1992;54:449-59.

5. Naylor CD, Lichtenstein SV, Fremes SE, Warm Heart Investigators. Randomized trial of normothermic versus hypothermic coronary bypass surgery. Lancet 1994;343:559-63.

6. Menasché P, Dunica S, Kural S, Touchot B, Chollet A, Steg $\mathrm{G}$, et al. An asanguineous reperfusion solution: an effective adjunct to cardioplegic protection in high-risk valve operations. J Thorac Cardiovasc Surg 1984;88:278-86.

7. Foglia RP, Steed DL, Follette DM, DeLand E, Buckberg GD. Iatrogenic myocardial edema with potassium cardioplegia. J Thorac Cardiovasc Surg 1979;78:217-22.

8. Tranum-Jensen J, Janse MJ, Fiolet JWT, Krieger JC, D'Alnoncourt CN, Durrer D. Tissue osmolality, cell swelling, and reperfusion in acute regional myocardial ischemia in the isolated porcine heart. Circ Res 1981;49:364-81.

9. Jennings RB, Schaper J, Hill ML, Steenbergen C, Reimer KA. Effects of reperfusion late in the phase of reversible ischemic injury: changes in cell volume, electrolytes, metabolites, and ultrastructure. Circ Res 1985;56:262-78.

10. Demaureux N, Grinstein $\mathrm{S} . \mathrm{Na}^{+} / \mathrm{H}^{+}$antiport: modulation by ATP and role in cell volume regulation. J Exp Biol 1994;196: 389-404.

11. Anderson SE, Murphy E, Steenbergen C, London RE, Cala PM. $\mathrm{Na}^{+} / \mathrm{H}^{+}$exchange in myocardium: effects of hypoxia and acidification on $\mathrm{Na}^{+}$and $\mathrm{Ca}^{2+}$. Am J Physiol 1990;259: C940-8.

12. Piper HM, Balser C, Ladilov YV, Schäfer M, Siegmund B, Ruiz-Meana $\mathrm{M}$, et al. The role of $\mathrm{Na}^{+} / \mathrm{H}^{+}$exchange in ischemia-reperfusion. Basic Res Cardiol 1996;91:191-202.

13. Inserte $\mathrm{J}$, Garcia-Dorado D, Ruiz-Meana $\mathrm{M}$, Solares $\mathrm{J}$, Soler-Soler J. Role of $\mathrm{Na}^{+} / \mathrm{H}^{+}$exchange occurring during hypoxia in the genesis of reoxygenation-induced myocardial edema. J Mol Cell Cardiol 1997;29:1167-75.

14. Scholz W, Albus U, Counillon L, Gögelein H, Lang H-J, Linz W, et al. Protective effects of HOE642, a selective sodiumhydrogen exchange subtype 1 inhibitor, on cardiac ischaemia and reperfusion. Cardiovasc Res 1995;29:260-8.

15. Ruiz-Meana M, Garcia-Dorado D, González MA, Barrabés
JA, Soler-Soler J. Effect of osmotic stress on sarcolemmal integrity of isolated cardiomyocytes following transient metabolic inhibition. Cardiovasc Res 1995;30:64-9.

16. Garcia-Dorado D, González MA, Barrabés JA, Ruiz-Meana M, Solares J, Lidon R, et al. Prevention of ischemic rigor contracture during coronary occlusion by inhibition of $\mathrm{Na}^{+} / \mathrm{H}^{+}$exchange. Cardiovasc Res 1997;35:80-9.

17. Garcia-Dorado D, Théroux P, Muñoz R, Alonso J, Elizaga J, Fernandez-Avilés J, et al. Favorable effects of hyperosmotic reperfusion on myocardial edema and infarct size. Am J Physiol 1992;262:H17-22.

18. Drewnoska K, Clemo HF, Baumgarten CM. Prevention of myocardial intracellular edema induced by St. Thomas' Hospital cardioplegic solution. J Mol Cell Cardiol 1991;23:121521.

19. Myers ML, Karmazyn M. Improved cardiac function after prolonged hypothermic ischemia with the $\mathrm{Na}^{+} / \mathrm{H}^{+}$exchange inhibitor HOE694. Ann Thorac Surg 1996;61:1400-6.

20. Shipolini AR, Avkiran M, Edmondson SJ, Hearse DJ, Galiñanes $\mathrm{M}$. Addition of $\mathrm{Na} / \mathrm{H}$ inhibitor to cardioplegia enhances myocardial preservation in a temperature-independent manner [abstract]. Circulation 1996(suppl 1);94:I536.

21. Hendry PJ, Masters RG, Haspect A. Is there a place for cold crystalloid cardioplegia in the 1990s? Ann Thorac Surg 1994;58:1690-4

22. Kay HR, Levine FH, Fallon JT, Grotte GJ, Butchart EG, Rao S, et al. Effect of cross-clamp time, temperature, and cardioplegic agents on myocardial function after induced arrest. J Thorac Cardiovasc Surg 1978;76:590-603.

23. Rubboli A, Sobotka PA, Euler DE. Effect of acute edema on left ventricular function and coronary vascular resistance in the isolated rat heart. Am J Physiol 1994;267:H1054-61.

24. Godt RE, Maughan DW. Influence of osmotic compression on calcium activation and tension in skinned muscle fibers of the rabbit. Pflugers Arch 1981;391:334-7.

25. Zhao M, Sonnenblick EH, Zhang H, Eng C. Increase in myofilament separation in the "stunned" myocardium. J Mol Cell Cardiol 1992;24:269-76.

26. Ben-Haim SA, Hayam G, Edoute Y, Better OS. Effect of hypertonicity on contractility of isolated working rat left ventricle. Cardiovasc Res 1992;26:379-82.

27. Anderson SE, Johnson JA. Tissue-fluid pressure measured in perfused rabbit hearts during osmotic transients. Am J Physiol 1987;252:H1227-37.

28. Whalley DW, Hemsworth PD, Rasmussen HH. Sodiumhydrogen exchange in guinea-pig ventricular muscle during exposure to hyperosmolar solutions. J Physiol 1991;444:193212.

29. Walters HL 3rd, Digerness SB, Naftel DC, Waggoner JR 3rd, Blackstone EH, Kirklin JW. The response to ischemia in blood perfused vs crystalloid perfused isolated rat heart preparations. J Mol Cell Cardiol 1992;24:1063-77.

30. Ohashi T, Yamamoto F, Yamamoto H, Ichikawa H, Shibata T, Kawashima Y. Transient reperfusion with acidic solution affects postischemic functional recovery: studies in the isolated working rat heart. J Thorac Cardiovasc Surg 1996;111: 613-20. 